\title{
Predictive value of cardiac magnetic resonance for the diagnosis and surgical relief of pericardial constriction
}

\author{
Kate Hanneman ${ }^{1 *}$, Hadas Moshonov ${ }^{1}$, Rachel M Wald ${ }^{1,2}$, Elsie T Nguyen ${ }^{1}$, Kim A Connelly ${ }^{3}$, Andrew M Crean ${ }^{1,2}$ \\ From 16th Annual SCMR Scientific Sessions \\ San Francisco, CA, USA. 31 January - 3 February 2013
}

\section{Background}

The diagnosis of pericardial constriction (PC) remains challenging and cardiac magnetic resonance (CMR) is increasingly used as a diagnostic tool. The objective of this study was to evaluate CMR findings for the prediction of subsequent surgical pericardiectomy.

\section{Methods}

CMR studies of 36 patients referred to assess for PC were evaluated retrospectively. Patients were divided into two groups depending on whether they subsequently had their pericardium stripped $(n=18)$ or did not $(n=18)$. IVC and aortic areas were determined by manual contouring on a single axial-SSFP image in maximum systole at the level of the esophageal hiatus. The ratio of IVC to aortic (I:A) area was calculated. Cross-sectional areas were indexed to body surface area (BSA). Quantitative data was assessed with a two-sample $t$-test and qualitative data was assessed with Fisher's exact test. A logistic regression model was used to determine the predictive probability of surgical pericardiectomy based on CMR features. Odds ratios (ORs) were calculated and receiver operating characteristic (ROC) analysis was performed.

\section{Results}

Mean age of patients was $53.9 \pm 15.3$ years, $72 \%(n=26)$ male, with no significant difference in mean age between the two groups ( $\mathrm{p}=0.429)$. In patients with constriction, the underlying etiology was idiopathic $(39 \%, n=7)$, infectious $(28 \%$, $\mathrm{n}=5)$, post-surgical $(17 \%, \mathrm{n}=3)$, connective-tissue disease $(11 \%, \mathrm{n}=2)$, and post-radiation $(6 \%, \mathrm{n}=1)$. IVC area, indexed IVC area, I:A ratio, pericardial thickness, RV area and indexed RV area were significantly different in patients who underwent pericardiectomy compared to those who did not (Table 1). Pericardiectomy was significantly associated with pericardial enhancement $(\mathrm{p}=0.011)$ as well as septal bounce $(p<0.0001)$. The odds ratio (OR) for undergoing pericardiectomy in patients with septal bounce was 289 (95\% confidence interval (CI) $(16.681,5007)$. Using ROC analysis, the area under the curve (AUC) and $95 \%$ CI for the prediction of pericardiectomy was $0.968(0.92,1.00)$ for IVC area, $0.932(0.86,1.00)$ for indexed IVC area and 0.963 $(0.91,1.00)$ for I:A ratio (Figure 1). An IVC area of $7.0 \mathrm{~cm}^{2}$ had $92 \%$ accuracy (sensitivity $=94 \%$, specificity $=89 \%$ ), an indexed IVC area of $3.4 \mathrm{~cm}^{2} / \mathrm{m}^{2}$ had $86 \%$ accuracy (sensitivity $=94 \%$, specificity $=78 \%$ ) and a I:A ratio of $1.8 \mathrm{had}$ $92 \%$ accuracy (sensitivity $=89 \%$, specificity $=94 \%$ ).

\section{Conclusions}

Multiple CMR features are potential predictors of need for surgical relief of pericardial constriction. Measurement of IVC cross-sectional area is both sensitive and specific for the diagnosis of constriction and we propose an optimal cut-off value of $7 \mathrm{~cm}^{2}$ for absolute area or $3.4 \mathrm{~cm}^{2} / \mathrm{m}^{2}$ when indexed to BSA.

\section{Funding}

None. 
Table 1 Quantitative CMR measurements and p-values from the two-sample t-test comparing patients who underwent pericardial stripping to those who did not.

\begin{tabular}{|c|c|c|c|c|c|c|c|c|c|}
\hline & \multicolumn{4}{|c|}{ Pericardium stripped $(n=18)$} & \multicolumn{4}{|c|}{ Not stripped $(n=18)$} & \multirow[b]{2}{*}{ p-value } \\
\hline & Mean & SD & Min & Max & Mean & SD & Min & Max & \\
\hline IVC area $\left(\mathrm{cm}^{2}\right)$ & 9.59 & 2.59 & 6.3 & 14.6 & 5.02 & 1.36 & 3.0 & 7.5 & $<0.001^{*}$ \\
\hline Indexed IVC area $\left(\mathrm{cm}^{2} / \mathrm{m}^{2}\right)$ & 4.93 & 1.47 & 3.1 & 7.9 & 2.77 & 0.74 & 1.4 & 4.0 & $<0.001^{*}$ \\
\hline I:A ratio & 2.56 & 0.76 & 1.4 & 4.0 & 1.28 & 0.27 & 0.7 & 1.8 & $<0.001^{*}$ \\
\hline Maximum pericardial thickness $(\mathrm{mm})$ & 5.50 & 2.77 & 2 & 12 & 1.72 & 0.57 & 1 & 3 & $<0.001^{*}$ \\
\hline RA AP diameter $(\mathrm{cm})$ & 5.17 & 1.15 & 3.2 & 7.9 & 5.00 & 1.21 & 3.1 & 6.9 & 0.664 \\
\hline RA TV diameter $(\mathrm{cm})$ & 4.81 & 0.91 & 3.4 & 6.4 & 4.99 & 1.18 & 2.7 & 8.4 & 0.605 \\
\hline RA area $\left(\mathrm{cm}^{2}\right)$ & 20.49 & 8.52 & 7.3 & 40.7 & 22.24 & 8.62 & 9.0 & 43.1 & 0.546 \\
\hline Indexed RA area $\left(\mathrm{cm}^{2} / \mathrm{m}^{2}\right)$ & 10.31 & 3.83 & 4.8 & 19.0 & 12.02 & 4.22 & 6.0 & 22.8 & 0.209 \\
\hline $\mathrm{RV}$ area $\left(\mathrm{cm}^{2}\right)$ & 15.86 & 6.31 & 9.3 & 29.7 & 22.11 & 6.38 & 13.6 & 34.0 & $0.006^{*}$ \\
\hline Indexed RV area $\left(\mathrm{cm}^{2} / \mathrm{m}^{2}\right)$ & 7.95 & 2.77 & 4.8 & 14.4 & 12.13 & 3.35 & 7.3 & 18.5 & $<0.001^{*}$ \\
\hline
\end{tabular}

$\mathrm{SD}$, standard deviation; Min, minimum value; Max, maximum value; RA, right atrium; AP, anterior posterior; TV, transverse; RV, right ventricle. *Denotes statistically significant result $(p<0.05)$

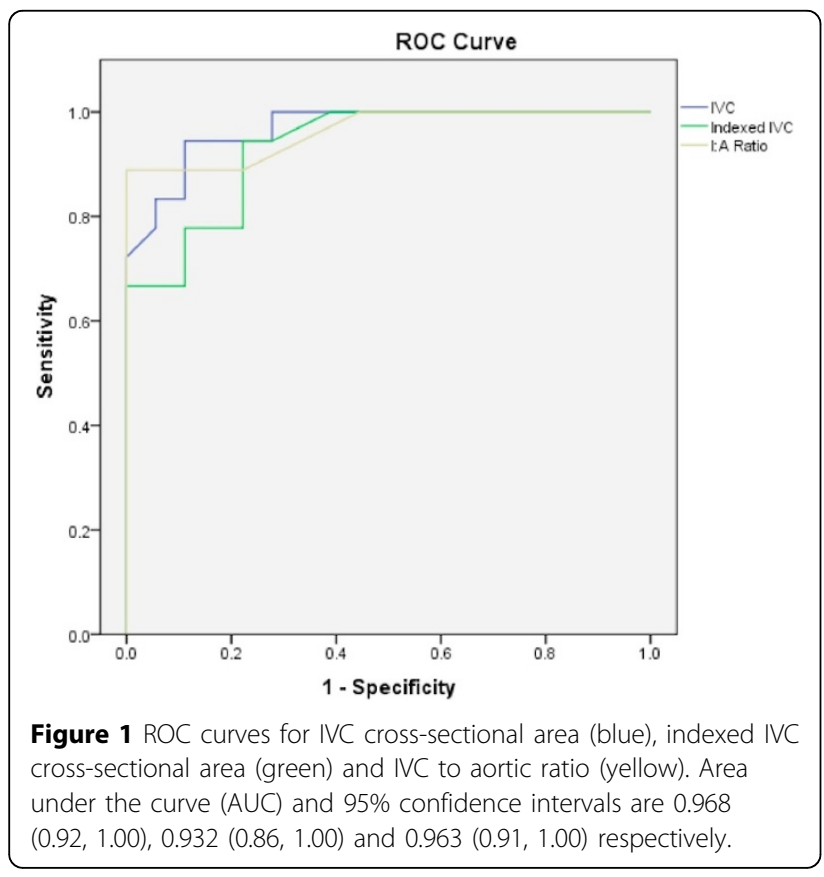

\section{Author details}

'Department of Medical Imaging, University Health Network, University of Toronto, Toronto, ON, Canada. ${ }^{2}$ Division of Cardiology, Peter Munk Cardiac Centre, Toronto General Hospital, University Health Network, University of Toronto, Toronto, ON, Canada. ${ }^{3}$ Division of Cardiology, St. Michael's Hospital, University of Toronto, Toronto, ON, Canada.

Published: 30 January 2013

doi:10.1186/1532-429X-15-S1-P107

Cite this article as: Hanneman et al:: Predictive value of cardiac magnetic resonance for the diagnosis and surgical relief of pericardial constriction. Journal of Cardiovascular Magnetic Resonance 2013 15(Suppl 1):P107.
Submit your next manuscript to BioMed Central and take full advantage of:

- Convenient online submission

- Thorough peer review

- No space constraints or color figure charges

- Immediate publication on acceptance

- Inclusion in PubMed, CAS, Scopus and Google Scholar

- Research which is freely available for redistribution 